\title{
Opportunities and barriers for successful return to work after acquired brain injury: A patient perspective
}

\author{
Marie Matérne ${ }^{\mathrm{a}, *}$, Lars-Olov Lundqvist ${ }^{\mathrm{a}, \mathrm{b}}$ and Thomas Strandberg ${ }^{\mathrm{b}}$ \\ ${ }^{a}$ University Health Care Research Center, Faculty of Medicine and Health, Örebro University, Örebro, Sweden \\ ${ }^{\mathrm{b}}$ School of Law, Psychology and Social Work, Örebro University, Örebro, Sweden
}

Received 9 July 2015

Accepted 12 May 2016

\begin{abstract}
.
BACKGROUND: Many people who suffer an acquired brain injury (ABI) are of working age. There are benefits, for the patient, the workplace, and society, to finding factors that facilitate successful return to work (RTW).

OBJECTIVE: The aim was to increase knowledge of opportunities and barriers for a successful RTW in patients with ABI. METHOD: Five men and five women with ABI participated. All had successfully returned to work at least 20 hours a week. Their experiences were gathered by semi-structured interviews, which were subsequently subjected to qualitative content analysis.

RESULTS: Three themes that influenced RTW were identified: individually adapted rehabilitation; motivation for RTW; and cognitive and social abilities. An individually adapted rehabilitation was judged important because the patients were involved in their own rehabilitation and required individually adapted support from rehabilitation specialists, employers, and colleagues. A moderate level of motivation for RTW was needed. Awareness of the person's cognitive and social abilities is essential, in finding compensatory strategies and adaptations.

CONCLUSIONS: It seems that the vocational rehabilitation process is a balancing act in individualized planning and support, as a partnership with the employer needs to be developed, motivation needs to be generated, and awareness built of abilities that facilitate or hinder RTW.
\end{abstract}

Keywords: Content analysis, vocational rehabilitation, qualitative interviews

\section{Introduction}

\subsection{Acquired brain injury}

Acquired brain injury (ABI) occurs as a result of a cerebrovascular accident, infection, tumor, intoxication, or trauma to the head [1]. In Western countries, ABI has an annual incidence of 100-300 per 100,000 population [2]. The yearly incidence of ABI in Sweden is $45,000-50,000[3,4]$, and approximately 5,000

\footnotetext{
*Address for correspondence: Marie Matérne, University Health Care Research Center, Box 1613, S-701 16 Örebro, Sweden. Tel.: +46196026266; Fax: +4619255559; E-mail: marie.materne@regionorebrolan.se.
}

of affected persons are of working age, between 18 and 65 years old [5].

Acquired brain injury is often a lifelong disability that entails a marked change in a person's life [6]. It involves all biopsychosocial levels [7, 8], with return to work (RTW) being a main goal for people with ABI $[9,10]$. In this study, RTW means return to previous work or to a new job, with at least $50 \%$ work time, and maintained working at least 1 year post-injury. It is regarded as a primary indicator of successful rehabilitation, thus serving as a proxy for recovery and a measure of rehabilitation. It affects the person's self-image, wellbeing, and life satisfaction, and leads the person to experience a state of normalcy in 
society, and become a symbol of success. People with ABI often experience difficulties to return to work [11]. In particular, marginalization at work affects identity and psychosocial wellbeing [12]. Therefore, successful RTW is important from an individual's perspective [13].

\subsection{Vocational rehabilitation}

The term vocational rehabilitation (VR) denotes all efforts to help someone to return to work and remain in work despite disability [14]. For people with brain injury, VR can be a struggle, and a challenging, longterm process $[15,16]$. In Sweden, the VR process involves many actors, such as the Swedish Social Insurance Agency, employers, and the health care system [17]. The Swedish Social Insurance Agency has been mandated to investigate the right to sickness benefits and coordinate them. The employer has the main responsibility for rehabilitation and needs to ensure that the workplace is suitably organized for people with disabilities [18].

Vocational rehabilitation is performed in collaboration with the local social insurance office. It is aimed at enabling the worker to resume work with his or her employer as soon as possible. Although no law demands that employers provide occupational health programs, small and medium-sized companies often share joint occupational health service centers. These service centers, in cooperation with health care, make assessments of a worker's ability to work and provide other types of support, such as individual counseling, physical training, and treatment [17].

\subsection{Previous research}

In a previous Swedish study [19], four out of five persons with stroke below 65 years of age still had cognitive dysfunction 1 year after the stroke; one of five was dependent in activities of daily living, and $20 \%$ had returned to employment after 3 years. Hence, people who went back to work several years after the injury often had a long rehabilitation with a work trial. Therefore, longer follow-up periods are needed $[15,19]$.

The ability to return to work varies across Europe, from about $65 \%$ in the Netherlands [20], to approx. $35 \%$ in Sweden [21, 22]. Studies from the US show a range, between $18 \%$ and $78 \%$ [20]. Vocational rehabilitation is time-consuming and the ability to return to work is enhanced by motivation and self-efficacy, in combination with external support [23]. When ABI patients describe the VR process they say that the hospital-based rehabilitation focuses on body functions and a return to daily activities rather than on RTW [23]. They also report a lack of information about their impairments. Hence, VR of individuals with $\mathrm{ABI}$ is a complex process and research aimed to understand mechanisms that underlie a successful RTW is warranted [24].

Previous qualitative research on VR after brain injury $[15,25,26]$ reports that information, long-term support, motivation, accommodating management, psychosocial perspectives at the workplace, and flexible working hours are important. These studies also highlight the social value of having a job, and the long-term efforts needed to return to the workplace. None of these studies have, however, been specifically directed at success of RTW in people with ABI. Therefore, the aim of this study is to increase knowledge about experiences of opportunities and barriers for a successful RTW in persons with ABI.

\section{Method}

This study is a qualitative, semi-structured interview study focusing on ABI sufferers' own experiences of VR. Semi-structured interviews are based on open-ended questions arranged in a logical order to cover the aim of the research. The intention of using semi-structured interviews is to learn more about subjective experiences. Semi-structured interviews were selected as a method because the intention was to get the participants to talk freely about their experience, within the structure of an interview guide [27]. This study is inspired by a hermeneutic theory of science, the purpose of which is to interpret, understand, and describe human experience [28].

\subsection{Participants}

Participants were recruited from an outpatient unit for people with mild and moderate brain injury in a county in Sweden (Table 1). According to the medical record, seven of the participants had had a mild, and three a moderate brain injury.

Inclusion criteria were: 18-65 years of age; RTW after ABI; participation in VR with successful results (i.e., had returned to pre-injury work or to a new job, with at least 20 hours per week at work, during 1 year); ability to communicate in spoken Swedish. The criterion of 20 hours was selected as an indicator for successful RTW. Before injury, all participants had 
Table 1

Participants' details

\begin{tabular}{|c|c|c|c|c|c|c|c|c|}
\hline No. & Diagnosis & $\begin{array}{l}\text { Degree } \\
\text { of injury }\end{array}$ & $\begin{array}{c}\text { Age at } \\
\text { interview, } \\
\text { yrs }\end{array}$ & Sex & $\begin{array}{l}\text { Years } \\
\text { since } \\
\text { injury }\end{array}$ & $\begin{array}{l}\text { Occupation at } \\
\text { the time of the } \\
\text { injury }\end{array}$ & $\begin{array}{l}\text { Occupation } \\
\text { after the } \\
\text { injury }\end{array}$ & $\begin{array}{c}\text { Working } \\
\text { time }(\%) \text { at } \\
\text { interview }\end{array}$ \\
\hline 1. & Stroke & Mild & 55 & $\mathrm{~F}$ & 4 & Study counselor & The same & $50 \%$ \\
\hline 2. & Stroke & Mild & 54 & M & 8 & Registered nurse & The same & $75 \%$ \\
\hline 3. & Stroke & Moderate & 27 & $\mathrm{~F}$ & 7 & Café assistant & Masseur & $50 \%$ \\
\hline 4. & Brain tumor & Mild & 47 & $\mathrm{~F}$ & 9 & Preschool teacher & School assistant & $50 \%$ \\
\hline 5. & Stroke & Mild & 41 & $\mathrm{~F}$ & 3 & Controller & The same & $100 \%$ \\
\hline 6. & Stroke & Moderate & 46 & M & 9 & Electrical fitter & Finance assistant & $50 \%$ \\
\hline 7. & Subarachnoid hemorrhage & Mild & 47 & $\mathrm{~F}$ & 5 & Logistician, transports & The same & $75 \%$ \\
\hline 8. & Stroke & Mild & 54 & M & 4 & Controller & The same & $100 \%$ \\
\hline 9. & Traumatic brain injury & Moderate & 50 & M & 6 & Information officer & Information assistant & $50 \%$ \\
\hline 10. & Traumatic brain injury & Mild & 44 & M & 5 & Technical fitter & The same & $75 \%$ \\
\hline
\end{tabular}

had the ability to work full-time (i.e., 40 hours per week). All participants had contact with the outpatient unit at the time of the interviews. Exclusion criteria were: known drug or alcohol abuse; and severe ABI or other illnesses (e.g., psychiatric diagnosis, neurological disorders) that could affect the possibility to return to work.

This study was approved by the regional ethical review board in Uppsala (reference No. 2008/349). Written informed consent was obtained from each participant before the interview.

\subsection{Procedure}

A purposive sampling was chosen to match the criterion of successful RTW [29]. The outpatient unit identified approximately 20 potential participants based on the inclusion criteria. Ten were identified to be contacted for participation in the study, five men and five women, aged 27-55. The team leader for the outpatient unit, a social worker, initially contacted the participants by telephone, and invited them to participate in the study. All gave permission to the researcher to contact them, first by letter and later by telephone, and all agreed to participate.

Interviews were conducted using an interview guide based on the study aim and questions concerning the aim [30]. The interview guide consisted of three key areas. The first was about background and consisted of questions about work before the injury, current work, and the perceived importance of work. Questions about VR in the second area included rehabilitation, planning of continued VR, adaptation, and aids. The third area was about working life, i.e., about how the participants were treated at work, about support persons at the workplace, and the future in terms of their career. The goal of the interviews was that the participants would talk as freely as possible, but still stay within the boundaries of the key areas [27, 30]. The participants were free to decide where the interviews would take place. Seven chose to be interviewed at their workplace. Two interviews were held at the researcher's office, and one at the participant's home. Each interview lasted 60-90 minutes. All interviews were conducted by the same interviewer (T.S.), and were audio-recorded, and transcribed by a secretary. During the interviews, the researcher continued until the researcher decided that saturation had been reached [30].

\subsection{Analysis}

Qualitative content analysis, as described by Graneheim and Lundman [31], was used to analyze the data material. Content analysis can capture variations between the transcribed interviews, which was considered an advantage in this study. The data was structured using the qualitative software program Nvivo10 (QSR International, Inc., Cambridge, MA, USA) to support the analysis. Two researchers (M.M., T.S.) worked in parallel during the analysis to reduce the risk of any item being lost or being inadvertently added to the material $[31,32]$.

In content analysis, the unit of analysis is the transcribed interview text [31]. The interview transcriptions were read and reread in order to gain an overall sense of the content. Data was in the first step grouped by content area of the interview guide. Thereafter, in the second step, the creation of meaning units began, within each content area. A meaning unit is a meaningful part of the text that is shortened into a condensed meaning unit, an abstraction of the text while preserving the essential content, as described in the literature $[27,31]$. The third step was to create codes, which are labels of condensed meaning 
units [31]. Codes with similar content formed subcategories. These were, in the fourth step, combined into categories. Categories represent a descriptive level and should contain as little interpretation as possible [31]. The fifth step of the analytical process was creating themes, which describe the content of all interviews [27, 31]. The first and third author (M.M., T.S.) cooperated in the fifth step to formulate the themes.

\section{Results}

Three themes were identified, capturing the essence of the material: (i) individually adapted rehabilitation; (ii) motivation for RTW; and (iii) cognitive and social abilities. These themes summarize the findings of the empirical material and address the aim regarding opportunities and barriers for successful RTW. All themes included opportunities and barriers, depending on how they had been adapted to the person's individual circumstances.

\subsection{Individually adapted rehabilitation}

This theme includes the following categories: transparency and dialog; demanding to be the driving force or receiving individually tailored rehabilitation; conditions for staying in work; attitudes of empathy or lack of empathy; modification of tasks and working time.

\subsubsection{Transparency and dialog}

All participants mentioned a successful VR process with a high level of transparency and dialog between all involved (i.e., the authorities, their colleagues, and themselves). They described their relation and interaction with the administrators, at the Swedish social insurance agency, and at the Swedish public employment services, as meaningful, respectful, and positive. The participants described different kinds of valuable support (e.g., from support persons, from their training, and during rehabilitation). When RTW was most successful, the participants described it in terms of a partnership. One participant had experienced of two types of support, namely, from one administrator who seemed to not care at all, and from another who cared very much. She thought that the administrator who was engaged in the VR, and who followed up her progress, had given her good support.
I think that it's important that he followed up on me, to see how it's going. Because what I missed when I was at this company, they just let me go ... totally... without any idea about the disease I had. (Interviewee 3)

One participant said she did not think society supported her enough. She had had to become a driving force in her own VR process. She described how she and her relatives had to fight throughout the process, so that she could continue participating in society through employment. She wondered what would have happened without her fighting spirit and without help from her relatives.

One and a half years, I think, I had been at home when I began work training ... but it was stressful and I had to rethink... find by myself what to work with. (Interviewee 3)

\subsubsection{Demanding to be the driving force or receiving individually tailored rehabilitation}

All participants described different situations and reactions from employers and colleagues. One participant described a workplace that succeeded in supporting her return to work almost without her noticing the transition between job training and being integrated at work. In this case, her boss took the initiative, which to her made the RTW feel easier because she had less burden and felt welcome at the workplace.

And I was really scared the first time I went back to work ... but it turned out just like I had been there [visiting at coffee break]. We made a little contract [me and the boss] that I would go twice a week ... and at the beginning, I wouldn't have to say anything, only listen. But then it turned out that I stayed around and chatted with one person and another, and then ... my boss says, "Now you need to start work training again, because you are here all the time anyway." (Interviewee 1)

\subsubsection{Conditions for staying in work}

A male participant who had suffered the misfortune of being retrenched from work at the time of his ABI eventually received wage subsidies, which meant that he was under no pressure to perform at his new workplace. He could work at his own pace and leave his anxieties behind. The only concern he 
felt had to do with the fear that the Swedish public employment service might withdraw his wage subsidy because the present employer might not be able to afford to employ him any longer under the same conditions.

The job I have now is almost perfect for me. It's like, I have flexible hours and I can arrive at work at half past seven, half past eight, or half past nine, or so ... I have some tasks for example, that I can prioritize and work on ... if I don't feel able to concentrate. (Interviewee 6)

\subsubsection{Attitudes of empathy or lack of empathy}

The interaction between the person with brain injury and his or her colleagues will, in the best scenario, give a feeling of acceptance, support, and increased self-esteem. One of the participants described the support she had received from a colleague with personal experience of illness and sick leave. On her own initiative, this colleague became a support person, both for the participant and for the employer. The participant felt that this support from the colleague was something special, and it was important to know that someone else had made a successful RTW; it gave her a feeling of hope and success.

Yes, I think because she was also afflicted [with breast cancer] a few years ago and then she was also on sick leave from work ... and then, there wasn't anyone who called her at home.... So when she came back [to work], she decided that it would never happen again around her in her work department. (Interviewee 1)

\subsubsection{Modification of tasks and working time}

Nine of the participants mentioned that informing the workplace about the disability helped increase the likelihood of a positive attitude from colleagues and management, and of modification of tasks according to ability. Some provided this information themselves; some had help from the outpatient unit. One participant did not want to inform his colleagues or management about what the disability meant, as he had a high desire for privacy. He felt that his colleagues were treating him with poor understanding and ignorance, which became a barrier. Another participant told that some of her colleagues had found information about strokes to prepare themselves for meeting her in her new condition.
Yes, so tense and oh, they knew ... and they were really well informed. I don't know; they even had a workplace meeting about me and then they had read everything that they could find about strokes. (Interviewee 1)

The participants talked about adaptation of working hours to enable RTW. Six of the participants had jobs without clear deadlines, which meant that they could have flexible working time and feel free to conduct their work in their own time; they thought this was an advantage.

And we have tried different working hours ... and find that my best time is before noon. (Interviewee 4)

\subsection{Motivation for return to work}

This theme consists of the following categories: creating goals and boosting confidence; stimulating work tasks and recognition at work; changes in life values and lifestyle after injury.

\subsubsection{Creating goals and boosting confidence}

All participants talked about their motivation for work as a meaningful goal in life. This was based on the thought that if they could succeed in returning to work, everything in life would be back to normal, to the way it was before the injury. This was a driving force and boosted their confidence during the rehabilitation process.

I feel that, for me, the rehabilitation isn't quite complete or real until I am able to work fulltime... I might not get there, but my goal is to get back to full-time. (Interviewee 2)

But it could at the same time be a hindrance if the process went too fast and led to regress in the process. Five of the participants talked about setbacks during the process. They were motivated and had goals, but the VR became challenging. One described the consequences for her, which was that she felt depressed and had to reduce her working hours.

And then the demands started... I had really fought to get back to where I was [before the injury] and then I thought it was time. We had a lot to do here [at work] and I felt I should get back to work $75 \%$... but then I shouldn't have [done that]. (Interviewee 5) 
Creating goals in the VR process was important for at least eight of the participants. In general, the main goal was going back to work and most of the participants wanted to return to work full-time. One participant, who also had aphasia, used a picture to show her colleagues and the rehabilitation staff her goals. Once she had outlined her goals, she felt she could get support when her motivation was lower.

When you don't have language, you can use pictures. I had an old picture that I had worked on [earlier] at work. I made a picture of how I wanted it to be and I showed it to everyone. (Interviewee 1)

\subsubsection{Stimulating work tasks and recognition at work}

One participant said that she wanted to continue her professional development, but she felt she did not have the capacity. She could not manage to work more than $50 \%$, and had problems with cognitive functioning as well, which became an obstacle. Another participant was happy about feeling needed at work and said she liked the challenges she was given.

It is very valuable to go to work and feel appreciated for what you do, get challenges and develop. (Interviewee 4)

Good support at the work environment, in terms of creating a social context at work and also finding social acceptance among employers and relatives, was important. All participants described the feeling of being understood and accepted by their employer after ABI.

I had the advantage of having very understanding employers... I had many good colleagues who helped me a lot. (Interviewee 5)

\subsubsection{Changes in life values and lifestyle after injury}

Another issue that could affect the motivation for work was that, after an ABI, values change. Things in life that used to be important may not be important anymore and things that were not prioritized before injury suddenly become essential. For three of the participants, work had been the most important thing in life, pre-injury. After the injury, other values became important, such as family life and nature.
You appreciate things in a different way, differently to what you did before; otherwise you would take everything for granted. (Interviewee 7)

Six of the participants talked about finding strategies to improve their quality of life, which also included work. One man said that work, as it had become after injury, limited his leisure time. For him, time for resilience, respite, and exercise became more important post-injury, as did having a sustainable quality of life. If he did not have enough leisure time he could not manage to do good work and his family life was also impacted. That was the reason why he worked part time.

Then I get tired and it causes my family life to suffer and I don't have time to keep up with my physical rehabilitation. (Interviewee 9)

\subsection{Cognitive and social abilities}

This theme consists of the following categories: communication, learning and other cognitive difficulties; cognitive fatigue; and social dependence and lower self-esteem.

\subsubsection{Communication, learning and other cognitive difficulties}

All participants described in different ways how their cognitive impairments affected their ability to communicate and return to work. They also talked about their memory problems. To overcome some of these difficulties, they used Post-it ${ }^{\circledR}$ notes, cell phones, and colleagues as memory support, but still, memory problems persisted.

I forget meetings and appointments, sometimes I just can't remember. I can completely forget about what I was supposed to do in the next half an hour... and that is why I have this telephone set at 15 minute intervals. (Interviewee 5)

Cognitive difficulties, with memory problems and difficulties learning new things, were a hindrance for all the participants and made them more dependent on others. This barrier not only affected their ability to do their job, but also the ability to change work. Some described their fear of changes in the organization, and they feared applying for a new job. All changes meant new circumstances and new things to learn, e.g., new computer systems, new colleagues, and new routines. Such changes required more energy than they would have required pre-injury, and it also took 
more time to learn new things. Some said that it was very hard to discover that their memory was not the same and that learning new things, which used to be easy, no longer was.

I have difficulties learning new things ... but the things I knew before the brain injury, they are in my head. (Interviewee 10)

\subsubsection{Cognitive fatigue}

Cognitive fatigue-related problems include losing concentration and no longer being able to pay attention, which may affect the person's ability to work full-time. It is important for a person to get to know the extent of his or her disability after an ABI. All participants found strategies to make the best of their work situation despite their difficulties; but on the other hand, it was a struggle to adapt to the new situation. One participant described a solution to reduce the problem:

I have difficulties keeping focused on one thing... I usually have several assignments to work on at the same time... I'm able to work on one assignment for 1 or 2 hours and then put it aside, take the next assignment and work with that. (Interviewee 8)

\subsubsection{Social dependence and lower self-esteem}

All participants described lower self-esteem postinjury. They talked about their new circumstances and how they felt about themselves. Their pride and self-esteem had suffered and they also had lower confidence in their ability to cope with things. One of the participants described her situation at the workplace, which affected her self-esteem. She reported that it was difficult for her to explain about her brain injury as it was not visible. She related that her cognitive function also affected her self-esteem and her dependence on her colleagues. Colleagues at her workplace had made sharp comments and she thought they didn't know about her injury.

Sometimes I am hurt by such [dismissive] comments, and I don't even have the energy to explain [about the injury]. (Interviewee 4)

\section{Discussion}

The purpose of this study was to increase knowledge about opportunities and barriers for successful RTW in persons with ABI, based on their experiences. The main factors for successful RTW in this study were an individually adapted VR process, balanced motivation to return to work, and cognitive and social abilities.

Individually adapted rehabilitation means that the individual is in focus of the rehabilitation efforts and that adaptations to work and the life situation have to be made constantly. An individually adapted VR process is a multidimensional task. People with ABI need individually designed treatment [33]. The Swedish society tends to take an individualized work approach [34] where citizens constantly have to make choices. A person with ABI might have difficulties to personally make all these choices. Such a person might require help to make decisions and adjustments in the VR process [25]. This need for individualized support continues for a long time and the support system plays an important role in this process [35]. A solution for the participants' needs was found, in some cases, with support from a case manager who could coordinate the various partners cooperating in the VR process [36].

The participants talked about the importance of interactions with the authorities and their employer, supporting them in their VR process. They described these interactions as a partnership. A successful partnership assumes that there should be a long-term collaboration, involving two or more actors. It also assumes that the participants must be empowered to act on their own mandate; that all partners contribute with something; and that there must be a formal arrangement that allows the parties to make decisions together [37]. Successful partnerships are dependent on engagement, commitment, and trust [38]. In this study, the partnership with the outpatient unit was crucial for successful RTW. When critical points in the VR appeared, the outpatient unit would help with support through actions, for example by participating in meetings or getting in contact with the authorities.

Some participants talked about a good relationship with their employers, whereas others were afraid that reorganization and new tasks at work would be a hindrance, too complicated to manage. Other studies also found that it is important to have a relationship of confidence with the employer who cares about the employees' needs and wellbeing [26]. Employers face emotional and practical issues when supporting 
persons with stroke in returning to work [7]. In one study, employers said that they had a lack of knowledge and experience, and would welcome advice from clinicians [7].

All participants in this study talked about their motivation to return to work even if they struggled to balance work, family life, and leisure time. Participants felt that if they succeeded in getting back to work, everything would return to normal. This was a driving force also reported in other ABI research [15, $23,24]$. In this study, the participants explained that if the motivation is too high, however, this can lead to setbacks in the rehabilitation process, which can have a substantial impact on, and become a obstacle to, RTW. One participant especially talked about this high level of motivation and her setbacks led to depression, so she had to decrease her working time. Support and treatment from the outpatient unit or other authorities could perhaps prevent such setbacks.

One factor that the participants described that increased the motivation for RTW was the feeling of being accepted in society following the ABI. The social interaction with work colleagues was also important for many, as it provided satisfaction in life [39]. So was the struggle for a state of normalcy, and successful RTW became the proof of such normalcy [9].

All participants talked about their difficulties after the ABI. One of the factors that affected them was cognitive fatigue. Cognitive fatigue after brain injury is a common occurrence [40]. It can affect working as well as social capacity and can be disabling. All participants described cognitive fatigue, both at work and in life situations in general, for example in home situations. Knowledge about cognitive fatigue is important in understanding the consequences for the injured. This knowledge is important, not only for the injured themselves, but for rehabilitation actors and employers so that the injured person's work environment can be adjusted according to need. Some examples of how to make adjustments in the work environment were mentioned in the interviews, such as technical aids, and having flexible work hours, adjusted work tasks, and support. Other cognitive difficulties described by the participants have also been reported previously, and include difficulties with attention, memory, structure planning, and learning new things [24].

Ponsford et al. (2014) found that self-esteem often decreases after ABI, and this was also a finding in the present study [41]. For example, one woman said that she did not have the strength to explain the consequences of her injury to colleagues because of negative attitudes at work. She received support in giving information to her colleagues and employer, which reduced some of the misconceptions about $\mathrm{ABI}$, increased her self-esteem, and turned misunderstanding to understanding of how ABI really affects the possibility to successfully return to work.

The result can be categorized into two main areas: societal factors and personal factors. Regarding the first, individually adapted rehabilitation is society's responsibility. On the other hand, motivation for $R T W$, as well as cognitive and social ability, can be categorized as personal factors, in accordance with another study [26]. These findings could have complex, but attractive, consequences for persons with ABI: complex, because it is difficult to influence society's structures for people with ABI. Attractive, because, at a personal level, the findings suggest that persons with ABI can affect the result of their own VR process by stating what they need from the VR to be successful. Cognitive and social function can be managed with the right support and, given the right support, the patient with brain injury can learn to find a balance and the right amount of motivation for RTW.

\subsection{Methodological discussion}

In this study, a sample of ten participants was considered adequate, according to Kvale and Brinkmann [30]. To determine an adequate sample size in research is a matter of judgment and experience in evaluating the quality of the information [42]. The interviews were informative and extensive and the researchers judged that the data was sufficient for a qualitative analysis. In accordance with ethics principles, no more data than is necessary should be collected [43].

Participants in research projects can often change their stories from one telling to the next as new experiences cause them to see the nature of, and connection between, the events in their lives differently from one time to the next [44]. In this retrospective study, some of the participants had memory problems, which could have affected our findings. The aim was to study the participants' own experiences. One of the few techniques available for doing this is through interviews. The participants were all living with $\mathrm{ABI}$ and were having to deal with it in their working life and life in general, which suggests that these were experiences they would remember. 


\subsection{Future research}

Further research may focus on the role and function of a support person during VR, and the collaboration between society, support persons, and people with $\mathrm{ABI}$ in managing the VR process. Furthermore, it would be interesting to study how people with ABI could be empowered and participate more actively in their own VR.

\section{Conclusion}

An individually adapted VR process is, according to our findings, important for a successful RTW, which also means that the brain injured patient has to be involved in his or her own VR. Support from society, employers, colleagues, and relatives is important. Motivation for RTW is essential, but there has to be a balance in motivation, otherwise the motivation can turn into a hindrance. Goal setting is useful as a driving force and to increase motivation. Awareness of cognitive and social abilities is essential for finding strategies to handle different situations that occur in VR. The support may be organized as a long-term contribution to enable a successful RTW.

\section{Acknowledgments}

We acknowledge the valuable help of the outpatient unit. We extend our thanks to the interviewees who participated in this study. This study was supported by grants from the University Health Care Research Center, Region Örebro County Sweden, and the Swedish Association of Brain Injured and Families.

\section{Conflict of interest}

The authors report no conflicts of interest. The authors alone are responsible for the content and writing of the paper.

\section{References}

[1] Campbell M. Rehabilitation for traumatic brain injury: Physical therapy practice in context. Edinburgh: Churchill Livingstone; 2000.
[2] Fortune N, Wen X. The definition, incidence and prevalence of acquired brain injury in Australia. In. Canberra: Australian Institute of Health and Welfare; 1999.

[3] Kleiven S, Peloso PM, von Holst H. The epidemiology of head injuries in Sweden from 1987 to 2000. International Journal of Injury Control and Safety Promotion 2003;10:173-80.

[4] Lexell J, Lindstedt M, Sörbo A, Tengvar C. Farmakologiska möjligheter vid hjärnskadebehandling - Rätt läkemedelsval kan optimera rehabiliteringsinsatserna [Pharmacological possibilities in brain injury rehabilitation]. Lakartidningen 2007;104:2422-26.

[5] Norrving B. Förekomst i befolkningen: Stroke- vård, omsorg och rehabilitering [Presence in population]: Vårdalinstitutets, Tematiska rum; 2010.

[6] Treger I, Shames J, Giaquinto S, Ring H. Return to work in stroke patients. Disabil Rehabil 2007;29(17):1397-403.

[7] Coole C, Radford K, Grant M, Terry J. Returning to work after stroke: Perspectives of employer stakeholders, a qualitative study. J Occup Rehabil 2013;23(3):406-18.

[8] Shames J, Treger I, Ring H, Giaquinto S. Return to work following traumatic brain injury: Trends and challenges. Disabil Rehabil 2007;29:1387-95.

[9] Johansson U, Tham K. The meaning of work after acquired brain injury. Am J Occup Ther 2006;60(1):60-9.

[10] Alaszewski A, Alaszewski H, Potter J, Penhale B. Working after a stroke: Survivors' experiences and perceptions of barriers to and facilitators of the return to paid employment. Disabil Rehabil 2007;29(24):1858-69.

[11] Strandberg T. Vuxna med förvärvad traumatisk hjärnskada - omställningsprocesser och konsekvenser i vardagslivet: En studie av femton personers upplevelser och erfarenheter av att leva med förvärvad traumatisk hjärnskada [Adults with acquired traumatic brain injury] Örebro: Örebro; 2006.

[12] Martinsen R, Kirkevold M, Bronken BA, Kvigne K. Workaged stroke survivors' psychosocial challenges narrated during and after participating in a dialogue-based psychosocial intervention: A feasibility study. BMC Nurs 2013;12(1):22.

[13] Murphy L, Chamberlain E, Weir J, Berry A, NathanielJames D, Agnew R. Effectiveness of vocational rehabilitation following acquired brain injury: Preliminary evaluation of a UK specialist rehabilitation programme. Brain Inj 2006;20(11):1119-29.

[14] Waddell G, Burton AK, Kendall NAS. Vocational rehabilitation - what works, for whom, and when? London; 2008.

[15] Rubenson C, Svensson E, Linddahl I, Bjorklund A. Experiences of returning to work after acquired brain injury. Scand J Occup Ther 2007;14(4):205-14.

[16] Vestling M, Ramel E, Iwarsson S. Thoughts and experiences from returning to work after stroke. Work 2013;45(2):201$11,11 \mathrm{p}$

[17] SOU. Arbetslivsinriktad rehabilitering rapport $\mathrm{nr} 7$ [Vocational Rehabilitation]. Stockholm: Statens offentliga utredningar; 2011.

[18] Swedish Work Environment Authority. The Swedish Work Environment Act (1977:1160). Stockholm: Swedish Government; 1977.

[19] Hofgren C, Björkdahl A, Esbjörnsson E, StibrantSunnerhagen K. Recovery after stroke: Cognition, ADL function and return to work. Acta Neurol Scand 2007;115(2):73-80.

[20] van Velzen JM, van Bennekom CM, Edelaar MA, Sluiter JK, Frings-Dresen MW. How many people return to work 
after acquired brain injury? A systematic review. Brain Inj 2009;23(6):473-88.

[21] Vestling M, Tufvesson B, Iwarsson S. Indicators for return to work after stroke and the importance of work for subjective well-being and life satisfaction. J Rehabil Med 2003;35(3):127-31.

[22] Vestling M, Ramel E, Iwarsson S. Quality of life after stroke: Well-being, life satisfaction, and subjective aspects of work. Scand J Occup Ther 2005;12(2):89-95.

[23] Medin J, Barajas J, Ekberg E. Stroke patients' experiences of return to work. Disabil Rehabil 2006;28(17):1051-60.

[24] Stergiou-Kita M, Yantzi A, Wan J. The personal and workplace factors relevant to work readiness evaluation following acquired brain injury: Occupational therapists perceptions. Brain Inj 2010;24(7/8):948-58.

[25] Gilworth G, Phil M, Cert A, Sansam KA, Kent RM. Personal experiences of returning to work following stroke: An exploratory study. Work 2009;34(1):95-103.

[26] Lundqvist A, Samuelsson K. Return to work after acquired brain injury: A patient perspective. Brain Inj 2012;26(1314):1574-85.

[27] Richards L, Morse JM. Readme first for a user's guide to qualitative methods. Los Angeles: Sage; 2013.

[28] Ödman P-J. Hermeneutik och forskningspraktik [Hermeneutics and Research Practice]. In: Gustavsson B, editor. Kunskapande metoder inom samhällsvetenskapen. Lund: Studentlitteratur; 2004. pp. 71-93.

[29] Patton MQ. Qualitative research \& evaluation methods. 3 ed. London: SAGE; 2002.

[30] Kvale S, Brinkmann S. InterViews: Learning the craft of qualitative research interviewing. Los Angeles Sage Publications, cop; 2009.

[31] Graneheim UH, Lundman B. Qualitative content analysis in nursing research: Concepts, procedures and measures to achieve trustworthiness. Nurse Educ Today 2004;24(2):105-12.

[32] Elo S, Kyngäs $\mathrm{H}$. The qualitative content analysis process. J Adv Nurs 2008;62(1):107-15.

[33] Häggström A, Larsson Lund M. The complexity of participation in daily life: A qualitative study of the experiences of persons with acquired brain injury. J Rehabil Med 2008;40:89-95.

[34] Waddell G, Burton AK. Is Work Good for Your Health and Well-Being? London: The Stationery Office; 2006.

[35] van Velzen J, van Bennekom C, van Dormolen M, Sluiter J, Frings-Dresen M. Factors influencing return to work experienced by people with acquired brain injury: A qualitative research study. Disabil Rehabil 2011;33(23/24):2237-46.

[36] Hillborg H. Erfarenheter av rehabiliteringsprocessen mot ett arbetsliv: Brukarens och de professionellas perspektiv [Experience in rehabilitation process towards a working life]. Örebro: Örebro University; 2010.

[37] Pierre Jr. Partnerships in Urban Governance. Basingstoke: MacMillan Press Ltd.; 1998.

[38] Dowling B, Powell M, Glendinning C. Conceptualising successful partnerships. Health \& Social Care In The Community [serial online] 2004;12(4):309-17.

[39] Corrigan J, Bogner J, Mysiw WJ, Clinchot D, Fugate L. Life Satisfaction After Traumatic Brain Injury. J Head Trauma Rehabil 2001;16(6):543-55.

[40] Johansson B, Berglund P, Rönnbäck L. Mental fatigue and impaired information processing after mild and moderate traumatic brain injury. Brain Inj 2009;23(13/14):1027-40.

[41] Ponsford J, Kelly A, Couchman G. Self-concept and self-esteem after acquired brain injury: A control group comparison. Brain Inj 2014;28(2):146-54.

[42] Sandelowski M. Focus on Qualitative Methods; Sample Size in Qualitative Research. Res Nurs Health 1995;18:179-83.

[43] National Academies (U.S.) Committee on Facilitating Interdisciplinary Research Committee on Science E, and Public Policy (U.S.)National Academy of Sciences (U.S.)National Academy of EngineeringInstitute of Medicine (U.S.). Facilitating Interdisciplinary Research. Washington, DC, USA: National Academies Press; 2004.

[44] Sandelowski M. Rigor or rigor mortis: The problem of rigor in qualitative research revisted. Advances in Nursing Science 1993;16(2):1-8. 